\title{
La obra vocal de Juan Bautista Cabanilles en su contexto. Una reflexión sobre la práctica musical histórica
}

\author{
Autor: Dr. José Duce Chenoll. \\ Directores: Dr. Luis Antonio González Marín y Dr. Paulino Capdepón Verdú. \\ Institución: Universidad de Castilla-La Mancha. \\ Tribunal: Dr. Antonio Ezquerro Esteban (Consejo Superior de Investigaciones \\ Ciéntificas), Dr. Juan José Pastor (Universidad de Castilla-La Mancha) y Dra. Nieves \\ Pascual León (Conservatorio Superior de Música de Valencia). \\ Calificación: Sobresaliente cum laude.
}

Fecha de la defensa: 20 de septiembre de 2018.

\section{Resumen:}

El objetivo de la tesis doctoral que aquí se presenta ha sido el de ahondar en la obra vocal de Juan Bautista Cabanilles, una parte de su producción relegada históricamente a un segundo plano frente a la organística, y no por ello de menor calidad e interés.

El estudio de este corpus, formado por un total de diez obras de las cuales tres son litúrgicas (Misa a 6, Beatus vir a 12 de dos tenores y dos tiples, Magnificat a 12 de idéntica formación vocal) y el resto lo componen obras en romance de dedicación eucarística (dúo El galán que ronda las calles; tono a tres voces Son las fieras; los tonos a cuatro voces Atiende a mis suspiros, Arroyuelo no huyas y Mortales que amáis; villancico a once voces Mi esposo asesta sus flechas y el villancico a quince Ah de la región celeste) se ha planteado desde cuatro vías de trabajo totalmente complementarias: la documental, el estudio de las fuentes, la realización de una edición crítica y la experiencia performativa. 


\section{TESIS DOCTORALES}

Tras contextualizar social y culturalmente el mundo en el que vivió Cabanilles, a través del cual se ha querido describir el mercado musical hispánico, y por extensión el valenciano de finales del siglo XVII y principios del siglo XVIII, se ha dado paso a una revisión del apartado biográfico intentando esclarecer algunos de los aspectos sobre los que se cernían sombras de importancia, a ser estos su formación musical, un posible interinaje como maestro de capilla y el por qué de la composición de este grupo de obras de tipologías tan dispares. Para ello se ha procedido al vaciado de los libros de fábrica de la Catedral Metropolitana de Valencia, al estudio de las fuentes y un análisis musical y comparativo de las mismas en relación con la producción de los maestros coetáneos, tanto del ámbito nacional como local.

De este estudio se han podido dilucidar parentescos con la obra de Urbán de Vargas y Antonio Teodoro Ortells, poniendo en entredicho la posible formación con Onofre Guinovart, al tiempo que se ha podido corregir un error en la ubicación de las fuentes y, mediante un estudio caligráfico comparativo, se ha intentado demostrar la existencia de las únicas fuentes manuscritas de Cabanilles, las cuales están conservadas en el archivo de la catedral valenciana bajo la forma de borradores o "borrones".

Tras este primer acercamiento directo a la música vocal de Cabanilles, en el que se ha podido analizar un aspecto no existente en la producción de tecla como es el uso de la retórica musical aplicada a un texto, se ha querido tender un puente entre el Cabanilles organista y el productor de música canora mediante el análisis de los procesos constructivos en ambos repertorios. En este estudio se ha podido constatar cómo Cabanilles comparte idénticos procedimientos de creación melódica, como el uso del canto llano y de los bajos de danza, aunque el empleo del material compositivo no llega al extremo de préstamos directos entre ambos mundos.

Una vez planteada la base documental y analítica se ha procedido a la elaboración de una edición crítica que siguiera todos los parámetros musicológicos actuales. De este modo la presente tesis se ve completada con una herramienta útil para cualquier intérprete o investigador que quiera acercarse a este repertorio.

Para finalizar este viaje a través del mundo vocal de Cabanilles se procedió a la grabación, por primera vez, del total de la música trabajada. De esta manera se ha podido aportar una reflexión, derivada de la propia experiencia, sobre la práctica musical en el siglo XVII y el periodo del cambio dinástico. Esta experiencia performativa ha servido para darle vOz a un repertorio que nunca debió perderla y ha dejado un documento sonoro que hace de complemento perfecto a una tesis doctoral de tema musicológico. 